\title{
The sustainable future of the Scottish textiles sector: challenges and opportunities of introducing a circular economy model
}

\author{
Lynn Wilson
}

\begin{abstract}
Case description: Zero Waste Scotland introduced the concept of the circular economy to the Scottish textiles sector at events throughout 2013 to 2014. In April 2014, it commissioned research by independent consultants to examine the academic and industrial textile landscapes in Scotland, including developments in technical textiles and research into innovation in textile design and examples of circular economy models.

The research identified a number of initiatives, including projects producing an alternative to denim and one developing cavity wall insulation from processed natural fibres. It made recommendations to Zero Waste Scotland about shaping the future landscape of textile innovation in Scotland and also offered examples of the circular economy from Scandinavia that might be applicable.

Discussion and evaluation: The implementation of the circular economy into Scotland's textile sector, underpinned by the aforementioned initiatives, can learn too from its textile and fibre heritage. Zero Waste Scotland is implementing an action plan which will offer support to the textile industry exploring 'closed loop' manufacturing, as well as funds for fashion designers to explore concepts such as zero-waste pattern design, luxury apparel from alternative textiles such as recycled polyethylene terephthalate and natural fibres such as nettle. A master class skills programme, delivered by leading UK and international experts, will bring together industry, academia, and higher education professionals to engage in learning and information exchanges about the circular economy. This paper presents Zero Waste Scotland's role and the research findings.
\end{abstract}

Keywords: Circular economy; Scottish textiles sector; Closed-loop manufacturing

\section{Background}

Zero Waste Scotland (ZWS) was initially a programme of the Waste Resource Action Programme UK (WRAP UK). On 1 July 2014, ZWS was formally launched as an independent Scottish not-for-profit company.

On 11 February 2014, WRAP UK launched the Sustainable Clothing Action Plan, SCAP 2020 Commitment. Sixty-five signatories and supporters of the SCAP 2020 Commitment have pledged to reduce the carbon, water and waste footprints of clothing they supply or receive in the UK by $15 \%$ by 2020 . Six of these companies are from Scotland.

ZWS supports SCAP 2020 and WRAP UK's Love Your Clothes campaign 2014 to 2016. In 2014, its key partners

Correspondence: Iynn.wilson@zerowastescotland.org.uk

Zero Waste Scotland, Ground Floor, Moray House, Forthside Way, Stirling FK8 1QZ, UK were John Lewis and Young Scot, the Scottish Youth information portal for 11 to 26 year olds. Both organisations supported the ZWS organised 'Spring Clean Your Wardrobe Weekend'.

ZWS' textiles portfolio and work programme for 2014 to 2016 is managed by its Circular Economy Team, which also covers Oil and Gas Decommissioning and Circular Economy Business Models. It identified various economic reports available from Scottish Enterprise (SE) and Scottish Development International (SDI) on the textiles industry in Scotland ${ }^{\mathrm{a}}$. However, there are few reports related to circular economy innovation in textiles in Scotland and evidence of closed-loop manufacturing.

In April 2014, ZWS commissioned independent research consultants to undertake an examination of the academic and industrial textile innovation landscapes in

\section{Springer}

(c) 2015 Wilson; licensee Springer. This is an open access article distributed under the terms of the Creative Commons Attribution License (http://creativecommons.org/licenses/by/4.0), which permits unrestricted use, distribution, and reproduction in any medium, provided the original work is properly credited. 
Scotland, including developments in technical textiles and research into innovation in textile design.

The aim of the commissioned research was to contribute to informing the direction and development of the 2014 to 2016 work programme delivered by ZWS' Circular Economy Team with the textiles sector in Scotland. The report, submitted to ZWS August 2014, examined the circular economy in relation to the textiles sector in Scotland.

The circular economy is, of course, more than just another name for 'reuse'. The Ellen McArthur Foundation says of it:

The circular economy is a generic term for an economy that is regenerative by design. Materials flows are of two types, biological materials, designed to reenter the biosphere, and technical materials, designed to circulate with minimal loss of quality, in turn entraining the shift towards an economy ultimately powered by renewable energy. ${ }^{b}$

The report submitted to ZWS found that there are pockets of innovation in the textiles sector in Scotland that are contributing to a circular economy; however, mainly, the driver is a commercial business goal rather than corporate social responsibility. This may reflect the relative weakness of the Scottish textile industry over the last decade and the lack of an overarching strategic vision for the industry as well as one that is drawing on, and support of, academic research.

Specifically, the report noted variations within the Scottish textiles industry's four sub-sectors: design, heritage/aesthetic, manufacturing, and technical textiles.

It highlighted the following:

1. Examples of innovation or resource-efficient practice already happening in Scotland, such as (a) in its strong technical textiles - where opportunities may exist for closed-loop manufacturing and (b) computer-aided design.

2. Scotland should strengthen what it already does well and bolster its sustainability activities by linking to provenance, traceability, durability and quality.

3. But it also said that 'no true examples of circular economy business models in Scotland were identified'. To that end, it recommended that the search should be broadened to Europe.

4. It is hoped the creation of the Textiles Innovation Council will 'be instrumental in driving change towards a circular economy ${ }^{\mathrm{c}}$.

The report, together with ZWS' analysis of its work with the textiles sector up to 2014, highlighted the challenges, opportunities and innovations that can make the
Scottish textile industry more materially circular. For example, ZWS has been investigating innovative ways to protect and conserve resources and develop closed-loop manufacturing and high-value products and support services which contribute to a sustainable circular economy for the textiles sector.

In a broader context, this work is part of ZWS' support of the Scottish Government's Zero Waste Plan which has set ambitious targets to achieve $70 \%$ recycling and maximum 5\% to landfill by 2025 for all Scotland's waste. 'Safeguarding Scotland's Resources', launched on 9 June 2013, is the Scottish Government's programme to reduce waste and create a more productive and circular economy ${ }^{\mathrm{d}}$ with one clear benefit: 'There is a potential saving of $£ 2.9$ billion through straightforward resource efficiency that this programme will help tap.' The Scottish Government has sealed its commitment by being the first government to join the Ellen MacArthur Foundation CE $100^{\mathrm{e}}$.

\section{Case description}

The research submitted to ZWS has informed its work programme for 2014 to 2016 (published internally August 2014) in terms of themes, policy, master classes, training events, campaigns and engagement with both industry and academia. The key objectives of the programme include the following:

To scope the potential for fibre processing in Scotland and early enquiry around establishing a sustainability standard for Scotland

To showcase and pilot further industry models of a circular economy (CE) and resource-efficient good practice

To seek greater engagement of industry with academia in terms of CE practice and theory

ZWS' textiles portfolio includes the following:

- The Scottish textiles sector

- Bulky textile waste - carpets and mattresses, public sector uniform procurement

- Commercial and consumer behaviour change

ZWS feels that the textiles sector has a significant part to play since it is the seventh most important contributor to the Scottish economy, with an annual turnover of $£ 956$ million. Exports of Scottish textile products are valued at $£ 375$ million. There are over 570 companies directly employing around 9,000 people across Scotland, with $55 \%$ of Scottish textile companies having fewer than 10 employees.

In areas such as the Scottish Borders, 50\% of employment is within the textile industry. Recent investments from international global brands such as Chanel $^{\mathrm{f}}$ demonstrate 
the high value and lucrative position of the Scottish textiles sector. Chanel announced at the beginning of 2014 that they would create 100 new jobs over the next 3 years at their plant in Hawick.

Global economic trends too have had a positive impact on the luxury export side of the Scottish textiles sector. In October 2013, the sector reported a level of growth $12 \%$ above the 2020 target and as a result, it has revised its targets to achieve between $£ 1.2$ and $£ 1.5$ billion in turnover growth by 2020. These revised figures recognise the significant gains to be made in international trade, and a $50 \%$ increase in exports is predicted by $2017^{\mathrm{g}}$. Sixty-four percent of textile production in Scotland is for luxury export goods ${ }^{\mathrm{b}}$.

This increased productivity could contribute to the global waste and environmental impacts that textiles and apparel production create but it can be reduced through the design and manufacturing of products that follow circular economy guidelines or the creation of products with a low carbon impact. Scotland is already developing key products and customers in this market, such as hand-knitted apparel from Fair Isle and the Harris Tweed Authority, which reported an increase of $25 \%$ in sales in 2013.

The carbon and water impacts of the textiles supply chain and production are also significant, particularly within the luxury Scottish market, which relies heavily on importing all raw materials such as cashmere from Mongolia and China. Scotland imported $£ 1.4$ million of the highest-quality cashmere from Mongolia in 2012/ 2013, and the political importance of this was highlighted by a visit from a Mongolian government delegation to Scotland hosted by the Scottish Government in 2013

The implementation of the circular economy within the textiles sector not only relies on the aforementioned initiatives and ZWS' work programmes but could also benefit substantively from reflecting on how Scotland's four sub-sectors that the ZWS-commissioned report identified, mentioned above, could be integrated into such an approach.

ZWS introduced the concept of the circular economy to the Scottish textiles sector through a series of events during 2013 to 2014 which were well received by both industry and academia.

These events were delivered in partnership with the Scottish Textiles and Leather Association (STLA) and the Scottish Textiles Academic Group, as well as an introductory event related to the SCAP, delivered in partnership with WRAP. Matters discussed included the concept of the circular economy and the challenges and opportunities ahead for textile design and manufacturing at a national and global supply-chain level, as well as assessing the SCAP Commitment targets of $15 \%$ reduction in carbon, water and waste by 2020 .
The STLA events also gave the industry the opportunity to share their experiences and ideas as to how to make the industry more efficient. This included a case study delivered by the Scottish Leather Group presenting their 11 years' experience of working towards sustainability.

Feedback from these events identified the need for training and skills development in resource efficiency, sustainability and global design and manufacturing models such as closed loop. Training bodies such as Skills Development Scotland and the Scottish Textiles Academic Group, and other sector funding bodies such as Scottish Enterprise, have welcomed the opportunity ZWS is offering the textiles sector, via its master classes, to introduce new skills and global textile knowledge on the circular economy.

The ZWS-commissioned research also provided evidence of related change in other nations. Specifically, ZWS asked the researchers to show how Scotland could learn from, and adapt, closed-loop models throughout the design, manufacture and supply chain and to identify if there were any early adopters or textiles businesses currently working towards such models. The researchers were tasked with reviewing and referencing previous research by partner organisations such as WRAP UK and the Ellen MacArthur Foundation, and ongoing academic research that would help ZWS identify key interventions it could make to embed circular economy and resourceefficient business models in the textiles sector in Scotland.

The brief for the researchers was to identify three key areas of research:

1. To provide a summary of the academic and industrial textile innovation landscape in Scotland, including developments in technical textiles as well as research into innovation in textile design in Scotland

2. To present case studies that reflect the landscape of Scotland's textile industry in relation to innovation in resource-efficient and waste reduction practices that are, or could be, developed as models of good practice in the circular economy

3. To present recommendations for future areas of support in terms of resource efficiency and closed-loop textiles in Scotland

The research was required to conclude with recommendations for future engagement and demonstrate how ZWS can help shape the future landscape of textile innovation in Scotland in relation to the circular economy and closed-loop textile manufacturing. The research needed to align with, and reference evidence of, the global trends and examples of current closed-loop 
practice and circular economy textile models in other countries, including the UK, that could be applicable to Scotland.

The report's recommendations have informed ZWS's work programme 2014 to 2016 for the textiles sector on how to shape the future landscape of textile innovation in Scotland, and it offered relevant examples of the circular economy from Scandinavia and advised developing links with work being undertaken there. It identified nine companies as potential case studies. This paper presents four of those nine case studies and outlines developments with Scandinavia.

With the exception of one company, Kraft Architecture, whose objective is to recycle waste textiles into cavity wall insulation, no true examples of circular economy business models in Scotland were identified by the researchers. They then proposed that the project scope be broadened to Europe, arguing that the business environment is similar in landscape to Scotland and that any activities discovered might be transferable to the Scottish textile industry. They identified too ongoing projects that are exploring a number of initiatives, including producing an alternative to denim, an initiative first supported by WRAP UK and now being researched at Heriot-Watt University, Edinburgh.

\section{The four case studies}

\section{Dawn Ellams - PhD Candidate, Heriot-Watt University}

This research was sponsored by Lenzing AG to make 'denim' from TENCEL (Lenzing AG, Lenzing, Austria) using digital printing to impart the stone-washed look'. Given the high environmental impact of stonewashing denim, this could be a promising circular economy project if it is possible to commercialise it within Scotland. At present, the denim supply chains are located, typically, in countries such as Turkey, China or Pakistan. This work and research was further funded by WRAP through the Challenge Fund.

Jeans were created that have a cotton-like quality but only use one fifth of water, energy and chemicals needed to manufacture conventional jeans.

Manufacturing one pair of cotton denim jeans uses, on average, 42 litres of water and is energy intensive.

Conventional denim production methods can also require up to 15 dyeing vats and an array of harmful chemicals ${ }^{k}$.

The research identified several areas within the manufacturing process which offer opportunities for saving water and reducing carbon emissions.

\section{Kraft Architecture - entrepreneur/inventor}

Both virgin and waste wool and textiles can be converted into building insulation products, and there have been a number of attempts to set up businesses in Scotland supplying this as a product. Notable examples include Thermobond from Kraft Architecture (280 High Street, Glasgow G4 OQT, UK) and Earthwool ${ }^{\circ}$ from Knauf Insulation (PO Box 10, Stafford Road, St Helens, Merseyside, WA10, UK). Generally sustainable insulation products fail to compete on price with mineral wool, which is also principally derived from waste materials, and fail to compete on performance with engineered insulation materials. The resulting market is very small and tends to be limited to applications like historic property restoration where technical and commercial factors are less important than heritage.

Kraft Architecture is a sole practitioner company, although this is augmented by part-time help as the need arises. The business focuses on low-carbon and lowenergy housing and sustainable product development. The company started in 2009 and was awarded a SMART: SCOTLAND Feasibility Award in 2010 to develop the product from the concept.

One of the closed-loop products developed by Kraft Architecture is a natural fibre insulation that retails under the trade name 'Thermobond'. The insulation manufacturing process can work with a wide variety of waste streams including cellulose, cotton, wool, wood and polyester and so it can create insulation materials tailored for different applications. A research project undertaken by Glasgow Caledonian University measured the thermal conductivity of a range of waste products to verify their potential for use as insulation. All the selected materials compare favourably with glass fibre on this performance metric. Keeping the proportion of wool at $60 \%$ or greater ensures that product flammability and resistance to smouldering complies with the British Standard BS5803-4:1985.

The manufacture of Thermobond requires $90 \%$ less energy compared to typical mineral wool insulation. In use, its durability and moisture control properties allow for a higher level of building fabric performance over the life of the building. It is also soft to touch and nonirritant, making handling and installation simple. Thermobond is treated with non-toxic, naturally occurring boron salts to heighten its resistance to vermin and insects over the life of the product.

Samples of Thermobond have been produced in sufficient quantities for use in demonstration installations. Kraft Architecture has secured investment of about $£ 500,000$ from the recently created Construction Scotland Innovation Centre ${ }^{\mathrm{m}}$ and further funding is being considered by ZWS. This will include suitable machinery to make insulation materials from recycled materials in its equipment set. Whilst this will not provide a volume manufacturing facility, it will provide a route to further product development, as well as sufficient material for the occasional demonstration installation. 


\section{Turnberry Rug Works-Johnstons of Elgin - a closed-loop approach}

Turnberry Rug Works and Johnsons of Elgin are working collaboratively to achieve the up-cycling of cashmere.

Established in 1991, Turnberry Rug Works, based in Ayrshire, is a small-to-medium enterprise, well known for its rug-making expertise. Its products are aimed at the higher end of the market, being both handmade and often bespoke. Although most of its output uses merino wool, it can incorporate stones, leather, seashells, steel and glass, as well as silk, linen, worsted wools and felted yarns into the designs.

Johnstons of Elgin is a long-established knitwear manufacturer (since 1797) that specialises in cashmere products. The company is vertically integrated, with the incoming feedstock being cashmere sourced exclusively from Inner Mongolia. The company has both a knitting plant in Hawick and a weaving plant in Elgin.

Weaving and, to a lesser extent, knitting processes, produce waste that cannot easily be recycled. A common type of waste is selvedge, which is the semi-finished edge that is produced to stop the fabric from unravelling or fraying. The production of scarves produces long lengths of this material. Following a chance meeting, Johnsons of Elgin supplied samples of its scarf selvage to Turnberry Rug Works which, after some development work on the tufting machines, found it was able to use the selvage to manufacture rugs. Producing a rug using virgin cashmere would be a very expensive proposition; however, by using selvage, a luxurious product can be produced using material that would otherwise have been sold as waste. The rugs are currently in production and sold under the Ecochic brand.

\section{Keela International}

Keela International Ltd specialises in the manufacture of advanced clothing for outdoor wear. Customers include consumers, mountain rescue teams, police and military forces. This is a large but highly competitive market sector estimated to be worth about $€ 5$ billion in Europe alone. Because both the USA and European markets are saturated, effectively, innovation is important to help sustain market share. Manufacturer claims that can be used to promote sales include 'free of toxins, environmentally friendly materials and sourcing, temperature control, reduced friction, water and wind resistant, moisture management'. The differentiating characteristics of Keela include expertise in fabric technology and garment construction.

Keela was awarded the Queen's Award for Enterprise: Innovation for its System Dual Protection fabric. This consists of two fabrics with very different characteristics, separated by an air gap. Originally developed for a military customer, it is now part of Keela's consumer product range. Independent research, conducted by Leeds University and Niederrhein University of Applied Sciences, substantiated the claims made for the material in terms of its ability to keep the wearer dry from external water and comfortable by regulating internal moisture.

Most modern outdoor clothing is made from materials that are difficult to dispose of, except in landfill; therefore, the most sustainable option is to maximise the life of the garment. This requires the customer to follow specific instructions on washing and reproofing and adds to the unfavourable environmental impact through the use phase of the textile.

As part of the company's drive towards sustainability, they have committed to SCAP and are the only apparel manufacturer member from Scotland.

\section{International relations - Scandinavia}

The researchers suggested to ZWS the need to explore case studies in Europe that might provide inspiration and examples for Scottish textile businesses to follow. Scandinavia was the prime suggestion, and a number of examples of the circular economy in textiles were identified.

The Research Council of Norway (NICE) funded a 3year project (2010 to 2013) valued at $€ 500,000$, with a view to identifying and promoting the benefits of textiles made of Norwegian wool to local consumers. The budget was used to support a variety of promotional activities, including publishing a book, Ren ull (Pure Wool, Aschehoug). It is currently only printed in Norwegian, with a foreword in English by Prince Charles. Its approach is similar to the Campaign for Wool.

When the project ended, NICE wanted to continue its research and use the heritage and technology it had discovered to develop further consumer demand for Norwegian wool and create a label of provenance, similar to Harris Tweed, called the Nordic Swan Ecolabel. As part of this research, they chose to visit Shetland where fleece is gathered from over 700 crofters to produce Shetland wool.

Norway also developed a product which was given an international standard-approved Cradle to Cradle ${ }^{n}$. The Dutch airline, KLM, wanted to create Cradle to Cradle carpeting working with Desso. Norwegian wool was tested for chemicals, etc. and was approved. The research company brokered an introduction to NICE and ZWS and the potential to develop research collaborations around wool and revise the heritage of Scottish and Norwegian knitwear has been identified. In this way, each country can work towards a model of provenance, traceability, durability and quality, as per the four key values mentioned earlier that the ZWS-commissioned report recommends. 
Another example is the 'Aran jumper', a well-crafted, distinctively patterned garment, synonymous with Scotland and Ireland, that is constructed so soundly, it can be disassembled, unravelled and reknitted, thus demonstrating an excellent closed-loop process. Families often deconstructed two small garments, knitting them into one larger garment, as their needs dictated.

The challenge today is to see how that heritage and evidence of closed loop can be harnessed to the circular economy to achieve a sustainable future for the textiles sector.

There is scope too to draw on the cultural craft heritage of Scotland; for example, there is a demand for hand-crafted products that draw on that heritage and once declining Scottish skills such as hand knitting, which have been invigorated by knitwear design companies such as Di Gilpin, who currently employs 90 freelance hand knitters throughout Scotland. Similarly, Eribe knitwear has 200 registered hand knitters who can each generate income of between $£ 100$ to $£ 400$ per month producing contemporary Scottish knitwear for export, mainly to China and Japan. Through the support from Scottish Enterprise, companies such as Eribe have doubled their turnover in 5 years, mainly through exporting. ${ }^{\circ}$ These companies are challenged to source sustainable Scottish raw materials such as wool from Scotland (other than from Shetland) and a growing number of small sheep crofts. The textile sector has to be aware, however, that a revival in craft heritage matters has to consider existing industry frameworks. For example, since 1952, a sheep farmer with more than four sheep is required, legally, to sell wool only through the British Wool Marketing Board (BWMB). The penalty, if enforced, is still a 6-month jail term. In 1995, this legislation was relaxed to allow farmers to sell wool only for direct export. This was due to the low price, lack of demand and essentially oversupply, with BWMB not being able to clear the stocks.

\section{Discussion and evaluation}

The ZWS-commissioned research concluded that the Scottish textile industry is innovative in key sectors, particularly technical textiles and computer-aided design. However, in both cases, the overarching objective is either to increase business competitiveness or improve resource efficiency, rather than closed-loop sustainability. The report concluded that there is little innovation in business models or in new methods of making the sector more materially circular in ways that are commonly understood. It also concluded that Scotland has a strong technical textiles sector, and there may be specialist opportunities here for closed-loop recycling solutions.

It recommended that the Scottish textile industry should focus on strengthening what it already does well and bolster its sustainability activities by linking to provenance, traceability, durability and quality. Inspiration should come from the luxury goods sector and also, in a more modest way, from Scandinavian brands such as Filippa $\mathrm{K}$, where longevity is an explicit brand strategy.

ZWS has integrated the report recommendations into its work plan to March 2016. It will focus on five key areas:

1. Industry and academia - skills training

2. New business model research

3. Fibre-processing facility

4. Funding to experiment with closed-loop technologies and systems

5. Textiles and apparel

\section{Industry and academia - skills training}

A series of master classes will be delivered from April to December 2015. The topics and content for the master classes are based on an analysis of the key characteristics of Scottish textiles design and manufacturing that will enable resource efficiency and skills for a circular economy such as design for disassembly and fibre processing and resource efficiency topics such as zero-waste pattern design and new technologies in dyeing and printing. One master class, Dyeing and Chemical Processing, will introduce global brand research such as dry dyeing by Stella McCartney for Adidas (Amsterdam, the Netherlands) and focus on resource efficiency such as a reduction of effluent from chemicals.

The majority of the 16 places for each course will be allocated to industry, with a quarter allocated to academia and education leaders who are developing curricula. Attendance is by invitation and application and candidates need to evidence how they will cascade the learning within their business or within departments and to colleagues.

Each facilitator will be travelling to Scotland from other parts of the UK or Europe (where possible, webinars will be used). To maximise the purpose of each visit, a student lecture series will also be part of the package accommodating up to 200 students at each lecture. Edinburgh University, Heriot-Watt University, Glasgow School of Art and Duncan of Jordanstone College of Art and Design in Dundee have provisionally agreed to host the these lectures.

Skills Development Scotland has confirmed that it is complementary to the Scottish Textiles Skills Action Plan $^{\mathrm{p}}$ that has recently been funded by the Scottish Funding Council.

ZWS will source and invite experts from outside Scotland, and evaluation consultants will be appointed to assess the impact of the participants' learning experience and how they have cascaded their learning to other 
colleagues or implemented new skills in their business processes.

\section{New business model research}

ZWS has identified two textiles companies who would like to explore new business models, details of which will be published in $2015^{\mathrm{q}}$.

An example of a business model that was identified in the research and that has characteristics that could apply to Scotland is Waste to Wow! Established in 2013 and based in Italy, it is a start-up enterprise that has achieved the accolade of being winner of the 2014 European Social Innovation Competition, out of 1,254 entrants ${ }^{\mathrm{r}}$. Their take on recycling is slightly different in that their waste stream is textiles from high-end fashion manufacturers that have failed quality control checks. Normally, these garments would be destroyed to make sure there is no leakage onto the grey market. From Waste to Wow! assures confidential and controlled disposal by using the material to make new, limited edition textiles that they sell under the brand name Quid (Progetto Quid, Verona, Italy). Thus, their feedstock tends to be of much higher quality than most similar recycling operations based on this model.

Scottish textile manufacturers who supply luxury global brand textiles must destroy their seconds and textile waste to avoid grey market leakage. An interior textiles company and some apparel textile companies have asked ZWS for advice as to how to dispose of luxury brand seconds currently going to landfill or being incinerated.

\section{Fibre-processing facility}

ZWS is interested in exploring a fibre-processing facility in Scotland that would help tackle the large fraction of lower grade bulk textiles which currently go to landfill, including carpets, mattresses and post-industrial waste from the textile industry. It also offers the opportunity to develop investment and jobs in fibre reprocessing in Scotland, adding value to materials which are currently worth little. As an example, if $60 \%$ of mattresses can be recycled (7,200 tonnes equates to 335,000 units), direct jobs created are estimated at 80 based on the ZWS business case of 8 jobs per 34,200 units.

A fibre-processing facility would enable Scotland to process post-industrial and post-consumer products from throughout the UK and gain some of the market share that other areas of the UK benefit from. Cotton and polyester are, respectively, around half and one quarter of the UK clothing fibre mix and hence are the priorities for fibre processing. Mixed fibres such as wool and nylon are characteristic of carpet construction, and mixed fibre extrusion is still a developing area. In the case of carpets, Anglo Carpets in England employs 35 people to process 1,200 tonnes. Carpet
Cycle employs 50 people for 5,500 tonnes. Mid-point is one person per 75 tonnes processed.

The WRAP report, UK textile product flow and market development opportunities, has numerous recommendations regarding how the UK textiles market could be developed. ZWS' priority for this work, based on evidence in that WRAP report, is to investigate the potential for Scotland to reprocess cotton and polyester back to fibre or feedstock, at cost parity to virgin material. It is recognised that scale could limit the implementation of the reprocessing infrastructure and this may require a change of direction for this area of work.

The research areas for the fibre-processing facility are specific to the following:

- Identifying candidate technologies for fibre processing and identifying their needs for financial support to enable proof of design, trialling and scale-up

- A route map of the activities which might be needed to deliver a commercially viable service Following the identification of suitable technologies and their applicability to Scotland, a financial and economic assessment will need to be conducted.

\section{Funding to experiment with closed-loop technologies and systems}

Funding will be offered by ZWS to three projects through an open call for industry and academic partnership projects. Project proposals should explore the feasibility of a new textile product or process that demonstrates closed-loop design or manufacturing. Awards will favour technical and performance textile companies.

Projects should be completed in January to December 2015. They will be monitored and evaluated externally to capture shared learning and secondary outcomes that may not be evident from the trialling of a product or process. Funding will be allocated for external monitoring and evaluation. Those projects which prove feasible maybe further supported by ZWS and taken to prototype/trial stage.

There will be three themes:

1. Closed-loop manufacturing - companies that already manufacture textiles and have post-industrial waste going to landfill that they think has the potential to be reprocessed

2. Piloting technologies/products for disassembly companies that would like to trial technologies such as Wear2 microwave seam technology

3. Exploring new fibre opportunities - all proposals will be considered from recycled synthetic fibre to the introduction of large-scale natural fibre processing 


\section{Textiles and apparel}

Scotland has a strong fashion and textile design community, with 600 textile and fashion graduates every year and graduates such as Lauren Smith from Edinburgh College of Art winning the prestigious Gold Award at London Graduate Fashion Week 2013. ZWS would like to encourage designers working in Scotland to consider supply chain sustainability and research textile design and garment construction that relates to circular economic and resource-efficient practices in design such as design for disassembly and sourcing and designing with recycled yarns such as recycled P.E.T., as well as alternative fibre and plant dying processes.

ZWS will provide funding for designers to develop prototypes working towards a truly sustainable circular economy product and/or using alternative fibres to imported yarn with a heavy carbon footprint. Mentors will be provided for each winner. The challenge will be finding suitably knowledgeable mentors in Scotland in this field.

\section{Conclusions}

Given the increasing demand for Scottish textile products, ZWS' work programme 2014 to 2016, and recent discussions with NICE, Norway, the Scottish Government's policy for the textiles industry should consider the following:

- Does Scotland need its own sustainability standard? Will this help or hinder business and how important is it to the provenance of Scotland's textile industry?

- How viable are pilots with the Scottish textiles industry to introduce new technology trials that will develop closed-loop processes?

- Can we source international investment in Scotland that not only provides job security but also invests in new technology and skills for a circular economy?

ZWS' support for the textiles sector in Scotland is already established. The key challenge now is to take forward the five aforementioned action points and evaluate and evidence the impact of embedding a circular economy in those areas. This paper has outlined our approach, why we have chosen it, and how we plan to implement it. The specific context is the potential for business growth in the textile sector in Scotland, within the broader context of ZWS' support for the Scottish Government's commitment to its zero-waste targets for 2025. Measuring the impact of a circular economy approach is a task for the long term and we know from industry examples, such as TENCEL ${ }^{\circ}$ by Lenzing ${ }^{\mathrm{s}}$, that it can take up to 30 years to develop a product that revolutionises industry.
The production of TENCEL ${ }^{\circ}$ is revolutionary. The production process is based on a solvent spinning process and represents the greatest accomplishment in cellulosic fibre technology. The unique closed loop production process makes TENCEL $L^{\circ}$ the fibre of the future: eco-friendly and economical ${ }^{t}$.

Options for development and investment in Scotland, therefore, not only rely on ZWS and Scottish Enterprise and other development agencies but also require collaborations and investment from the rest of the UK, including further and higher education, and global partners. ZWS' work programme from 2014 to 2016 will produce evidence and provide incentives to the textiles sector that show our commitment to underpinning a circular economy.

ZWS is intent on supporting a sustainable industry that will generate long-term growth and be supportive of the Scottish Government's zero-waste targets. That can only come about by facing up the challenges and opportunities that a circular economy model, as per our work programme for 2014 to 2016, is intent on discovering. ZWS will maintain alliances with all the key stakeholders mentioned in this paper, as well as forge stronger connections with the industry and academia. In our view, the theory and practice engendered by that connection can establish a body of knowledge on the circular economy that will determine the Scottish textile industry's short-, medium- and long-term goals and secure its future sustainability.

\section{Endnotes}

${ }^{\mathrm{a} S}$ Cottish Textiles Strategy 2011 to 2015

bhttp://www.ellenmacarthurfoundation.org/

${ }^{\mathrm{c}}$ The Scottish textiles sector has been given $£ 750,000$ over 3 years to develop innovation and skills for industry. Heriot-Watt University, Edinburgh will administer the programme. Glasgow Clyde College will deliver an academy-style skills programme funded by a consortium of funders including Skills Development Scotland, and ZWS will be invited to a sub-group meeting when it is set up.

${ }^{d}$ http://www.gov.scot/Publications/2013/10/6262. Exploring the feasibility of circular economy business practices contributes to 'Safeguarding Scotland's Resources', Sections 6.1 Resource Efficient Scotland - Action 7 Business engagement and an early adopter network and Action 12 - Remanufacturing and new business models, 6.2 Stimulating innovation and business opportunities and the provision of technical master classes for the textile design and manufacturing sector supports and 6.3 Sustainab`le Design Action, Objective - to stimulate innovation in the design and manufacture of products and packaging - to engender a shift towards design for 
longevity, reassembly or remanufacturing and useable by-products, designing out wasted energy, materials and pollution. In addition, by inviting teaching staff in education and academia to participate in the master classes with industry, it also supports Action 18 - Public engagement and education. ZWS works closely with Education Scotland, Young Scot and the Ellen McArthur Foundation on these activities

ehttp://www.ellenmacarthurfoundation.org/about/media Richard Lochhead, Environment Secretary, statement on joining CE100 - 'Scotland's economy will benefit from moving to a more circular model of production and consumption. Our Zero Waste Plan is already delivering important actions to make better use of resources, and we can accelerate progress if we join together with others on a global level'

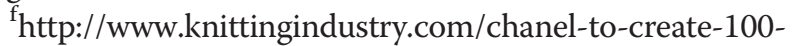
new-jobs-at-barrie-knitwear-in-scotland

${ }^{\mathrm{g}} \mathrm{http}$ ://news.scotland.gov.uk/News/Textiles-targetsuccess-564.aspx

${ }^{\mathrm{h}}$ Scottish Key Facts, compiled by the Economic Research Team, Scottish Enterprise, May 2014

${ }^{i}$ http://www.itv.com/news/border/story/2013-08-07/ mongolian-delegation-in-hawick/

'http://www.hw.ac.uk/news-events/news/wooden-denimto-cut-carbon-emissions-11090.htm - Dawn Ellams, Feb 2013

${ }^{k}$ http://www.hw.ac.uk/news-events/news/wooden-denimto-cut-carbon-emissions-11090.htm

${ }^{\mathrm{l}} \mathrm{http}$ ///www.cicstart.org/userfiles/file/AC-1-REPORT.PDF

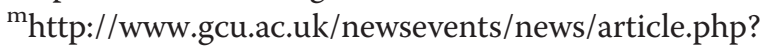
id $=73608$

${ }^{\mathrm{n}}$ http://www.c2ccertified.org/product_certification

${ }^{\circ}$ Scottish Enterprise case study

${ }^{\mathrm{P}}$ The Scottish Textiles Skills Strategy \& Action Plan has been developed to support the objectives of the industry strategy A Strategy for the Textiles Industry in Scotland 2011-15 (http://www.scottish-enterprise.com/ knowledge-hub/articles/publication/textiles-strategy-

2011-2015) and sets out the key skills priorities that the textiles sector must address in order to fulfil its growth potential

${ }^{\mathrm{q}} \mathrm{New}$ business models are covered by a wider stream of the Circular Economy Team and therefore, were not part of the commissioned textiles research, although there are relevant documents within the report

${ }^{\mathrm{r}} \mathrm{http}: / /$ socialinnovationcompetition.eu/401/

${ }^{\mathrm{s}}$ The Lenzing Group is a large publicly owned manufacturer of cellulosic fibres. It employs over 6,500 staff, making nearly 900,000 tons of fibres per annum, with sales of around $€ 2$ million per annum. Its three principal products, Viscose, Modal and Tencel are well known to the sustainable textile community. The feedstock is wood, sourced from sustainable forests. Fibre production by Lenzing achieves a wood utilisation rate of over $50 \%$. Co-products include furfural, xylose and acetic acid with the remaining parts used principally for energy production. In 2013, Lenzing launched a new fibre, EUROCEL, which is a 50/ 50 blend of Viscose and Tencel. The intended application is high-end non-wovens, mainly for hygienic applications as well as in the household and industrial sectors

thttp://www.lenzing.com/en/fibers/tencel.html

\section{Abbreviations}

BWMB: British Wool Marketing Board; CE: circular economy; KLM: Royal Dutch Airlines; NICE: The Research Council of Norway; PET: polyethylene teraphthalate; SCAP: Sustainable Clothing Action Plan; SDI: Scottish Development International; SDS: Skills Development Scotland; SE: Scottish Enterprise; STAG: Scottish Textiles Academic Group; STLA: Scottish Textiles and Leather Association; WRAP UK: Waste Resource Action Programme UK; ZWS: Zero Waste Scotland.

\section{Competing interests}

The author declares that she has no competing interest in relation to this study.

Received: 26 February 2015 Accepted: 2 April 2015

Published online: 24 June 2015

\section{Submit your manuscript to a SpringerOpen ${ }^{\circ}$ journal and benefit from:}

- Convenient online submission

- Rigorous peer review

- Immediate publication on acceptance

- Open access: articles freely available online

- High visibility within the field

- Retaining the copyright to your article

Submit your next manuscript at $\boldsymbol{\wedge}$ springeropen.com 